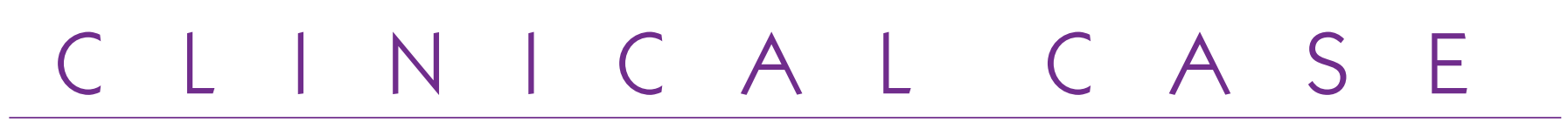

\title{
Optimizing the choices of extractions and mechanics: principles and a clinical case
}

\author{
J. FAURE \\ Private practice in Auch \\ Former University Senior Lecturer, University of Toulouse
}

\section{OPTIMIZED MANAGEMENT OF THE DIFFERENT CHOICES OF EXTRACTIONS AND MECHANICS}

\section{General Outline}

The increasingly stringent requirements of medical ethics forces us to choose:

- a treatment that has scientifically demonstrated its effectiveness (EBM);

- a treatment with the best risk/benefit relationship;

- a treatment based on a diagnosis and a complete prognosis in time and in space (predictive).

It further requires that we thoroughly inform the patient ("informed consent") of our choice and of the drawbacks, risks, etc.

Practitioners can no longer simply say "I have a severe anterior deficit: I will extract $4 \times 4$ and I will see afterwards followed by sending a letter asking for the sacrifice of $4 \times 8$ on the day of de-banding!
However, this is how choices are made in current practice:

- analysis of cases after eruption of the adult dentition, often incomplete (second molars not yet in place, or the premolars);

- possibly deciding to sacrifice the premolars based on the initial crowding and the objectives of incisor positioning. The loss of anchorage of the mandibular molars or their retraction is rarely thought of;

- prognostic evaluation of the potential for eruption of 38-48 at the end of multibanded treatment or later;

- enucleation of $4 \times 8$.

Today, making choices this way is no longer acceptable because too often it leads:

- to the extraction of 8 teeth when the anterior equilibrium is stable;

- or in sacrificing the objective of a stable 
anterior equilibrium (a policy of automatically aligning the teeth by advancement) to a relapse of the crowding by reducing extractions to only the 4 third molars.

Frequently, in these cases, an intelligent management of the problem of space would have allowed reducing the sacrifice to 4 premolars, while assuring the stability of the anterior alignment and conserving the 4 third molars. But a reasoned assessment of the mechanics is required.

The principles of medical ethics, a new consideration for our specialty, make us hesitate before choosing treatment that involves removing many teeth (4 premolars and 4 molars). Moreover, the analytical methods that we commonly use make it possible for us to make very precise choices and the development of mini-screws allows for improved management of space, with overall better treatment control between the loss of anterior and posterior room, and in order to limit the number of selective dental extractions.

These methods will be demonstrated with, in fine, the presentation of a case related to the discussion above.

\section{CHOICE OF EXTRACTIONS AND MECHANICS BASED ON THE BALANCE OF ANTERIOR AND POSTERIOR SPACE ARBITRATED BY THE "MOLAR CURSOR"}

\section{The determinants of the choice of extractions}

The choice of extractions is the fundamental choice from a clinical as well as legal standpoint. This choice must be made from the very beginning with a full range of options, it must be justifiable, it must have a timing known ab initio, and it must be explained to the patient:

The are only four possibilities;

- none;

-4 premolars;

-4 molars;

- 4 premolars and 4 molars.

The rule is: the optimal choice in this case is to have the minimal number of selective dental extractions for the chosen objective.

But the orthodontist in the majority of cases must manage:

- a problem of room (especially in

European ethnic groups);

- an anterior-posterior problem.
In managing this, there are two interdependent choices:

- extractions;

- mechanics.

But each of these choices is simultaneously dependent on the problem of room and the problem of the anterior-posterior discrepancy: we know for example that a strong anterior mandibular deficit is an indication for the sacrifice of the mandibular premolars (34-44) whereas a strong molar Class II indicates the sacrifice of 35-45 bringing with it the loss of anchorage.

\section{Optimized management of the Arch Length Discrepancy: the molar cursor}

In the optimal management of the ALD, the orthodontist is just like a gourmand who has spread too much jam on his toast: and by tilting the toast in an optimal way he tries to keep as 
little of the jam as possible from slipping off and only from one side.

In similar fashion, the orthodontist can move the molar cursor forward, for example, in order to increase the available space posteriorly by decreasing the available space anteriorly, or towards the posterior to increase the space available anteriorly at the cost of reducing the space available posteriorly.

We all understand that anteriorposterior mechanics has this type of effect but most orthodontists do not consider the mechanics in terms of numbers:

- Class II mechanics leads to a loss of mandibular anchorage, that aggravates the loss of room in the anterior region (Fig. 1). It calls therefore for anterior extractions;

- Class III mechanics leads to a retraction of the mandible and a posterior tip back, that exacerbates the loss of space in the posterior area. Therefore, posterior extractions are necessary. (Extractions distal to the molars).

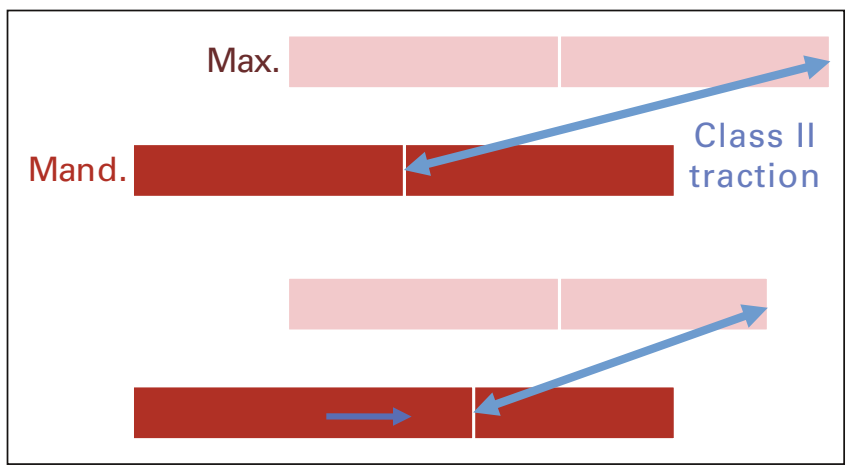

Figure 1

Effect of Class II mechanics on the molar shift: they aggravate the anterior deficit and median (mad) mandibular due to a loss of molar anchorage and improve the posterior deficit ( $p d)$.
These decisional criteria of loss versus gain of space are particularly useful in those cases in which the overall deficiency is close to the amount of space gained by the sacrifice of the premolars $(15 \mathrm{~mm})$ or close to the space gained by the sacrifice of the molars $(20 \mathrm{~mm})$.

In the first case we could move the molar cursor in such a way that only the premolars are removed, due to the increase of the posterior space that makes room for the third molars.

In the second case, we could retract the molar cursor in order to save the premolars by erasing the anterior deficiency and by accepting the sacrifice of "only" four molars (in general $4 \times 8$ ).

In this case, the intelligent management of the molar cursor helps us maximize (and minimize) the selected extractions: $4 \times 4$ or $4 \times 8$ instead of $4 \times 4+4 \times 8$.

The optimal management of the mechanics and of the extractions is dependent therefore on the calculations of space in each sector ( 2 boxes: mad box: anterior and median deficiency, and pd box: posterior deficiency). The measurement is composed of:

- filling the two boxes for the independent data of the treatment (crowding, Curve of Spee, etc.);

- a primary choice of extractions for the arch being studied;

- a consideration of the necessary anterior-posterior mechanics that can modify the distribution of the deficiencies (mad/pd);

- a potential reassessment (through feed-back), of the mechanics or of the extractions. Necessary Class II mechanics for example can:

- aggravate the mandibular mad due to a loss of mandibular anchorage; 
- relieve the space problem in the posterior mandible (pd).

\section{Anterior and median box (mad)}

We're using a standard box with typical categories:

- crowding;

- Curve of Spee;

- incisor repositioning;

- first molar repositioning;

- Class II intermaxillary traction (TIM II);

- premolar extractions $(+15 /-5$ or $+15 /-8)$.

Global molar mesialization is the sum of the mesial movements than can appear in lines 5 (TIM II or 6 [loss of systematic (system wide) anchorage without strong anchorage preparations such that extractions are done ( -5 or -8 $\mathrm{mm}$ ) or again with a positive value this time with 4 (repositioning the molars)]. Faced with a net negative box, we have to remember that:

- 1 and 2 correspond to the (nonmodifiable) data at the start;

- 6 and 5 can show a decrease in their negative impact, at the cost of reinforced anchorage (anchorage preparation, screws, etc.);

- 3 and 4 are the least susceptible to being modified:

- 3 ; this is the key to the equilibrium of the dentition; we can calculate the objective and therefore the value of the loss/gain of space according to the European norm or the compensations ("acceptable arrangements"); we use the calculations of the Steiner chevrons;

-4 ; retraction of the molars is a difficult task.

\section{Posterior box (pd)}

It classically includes according to Tweed-Merrifield, the following lines
(Fig. 2 and 4):

1. existing available posterior space. It is measured on the initial cephalometric film, distal to the posterior border of 37-47 up to the anterior border of the ramus, projected on the Tweed occlusal plane. We add the right and left measurements to determine the total mandibular space. In strong ALD, the number is negative;

2. the anticipated loss of anchorage: it is the inverse of the loss of total anchorage of the anterior box that appeared at lines 4, 5 and 6 . Thus, if the lines "TIM II" and "extractions" written "-4" and "+ 15/ -5 ", the loss of anchorage will be in sum - 9 for the anterior box and +9 for the posterior box;

3 . the sum of the mesio-distal diameters of 38-48;

4. the predicted posterior growth.

1 - 3 gives the current available space (8 impacted) or the deficiency if the result is negative.

$1-3+2+4$ gives the predicted available space at adulthood $(8 \mathrm{im}$ pacted) or the deficiency if the result is negative.

Two important remarks must be considered in order to use these calculations in a strict manner.

First, the Tweed calculation considerably underestimates the duration and the amount of posterior mandibular growth. We based these calculations on samples of 60 girls/ 60 boys. The median posterior growth between the orthodontic age of 12 years and the end of growth, towards 20 years, is $16.5 \mathrm{~mm}$ for boy and of $11.5 \mathrm{~mm}$ for girls.

The median posterior growth between the orthodontic age of 12 years 
and the end of growth, around 20 years is $16.5 \mathrm{~mm}$ for boys and $11.5 \mathrm{~mm}$ for girls. This allows us to make an initial "educated guess" estimate. If we take into account the age of the patient, the following regression equations provide the amount of overall space gained:

- male posterior growth $=33.03-$ $1.722 \times$ age;

- female posterior growth $=39.29-$ $1.755 \times$ age.

Then, fixing the posterior limit of the available space for the third molars at the anterior border of the ramus of

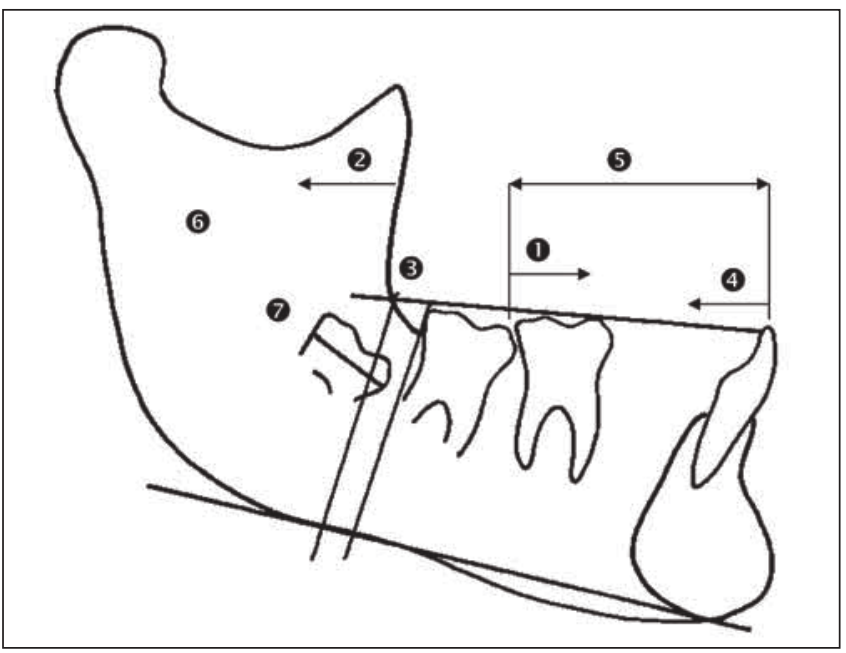

Figure 2

Prediction of eruption per-treatment:

1. Predicted molars mesialization.

2. Theoretical posterior growth after Merrifield or Oueiss-Faure.

3. Available retro-molar space/second molar

4. Predicted incisor repositioning laccording to the Steiner analysis by us).

5. Variation of arch length according to the Steiner box $(-1-4)$.

6. Mesio-distal diameter of the 8's.

Problems of anterior and median space (mad); mad:

- crowding -CdS - $4-1$.

Problems of posterior space (pd); pd present: $3-7$; estimated pd: $3+1+2-7$. the is exceptionally rigorous (Fig. 3): the terminal part of the arch and the ramus are in different parasagittal planes, and we clinically assess each day that the third molars can be perfectly functional, when viewed on the lateral head film in strict norma lateralis, they are covered up to 2 or $3 \mathrm{~mm}$ by the anterior border of the ramus (the median value of covering for the group "wisdom teeth aligned in the arch:" $6 \mathrm{~mm}$ ).

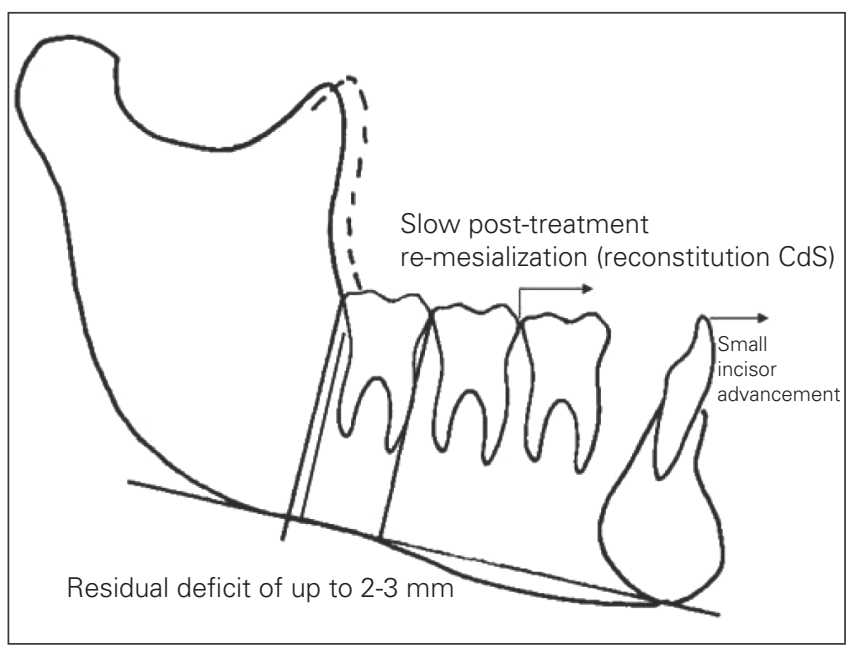

Figure 3

Late post treatment eruption and alignment of the 8's.

\begin{tabular}{|c|c|}
\hline Posterior box & \\
\hline $\begin{array}{l}\text { Actual Available Space (distal 7) } \\
\text { Diameter of } 3^{\text {rd }} \text { molars } \\
\text { Saving of existing space (+/-) }\end{array}$ & \\
\hline $\begin{array}{l}\text { Predicted growth } \\
\text { Loss of molar anchorage } \\
\text { Saving of predicted space }\end{array}$ & \\
\hline
\end{tabular}

Figure 4

Posterior box: pd. The posterior growth is calculated by:

Male posterior growth $=33.03-1.722 \times$ age;

Female posterior growth $=39.29-1.755 \times$ age . 
Moreover, the physiologic reconstruction of the post-treatment Curve of Spee at a much later time can allow a median mesial movement of the molars of $1 \mathrm{~mm}$.

We can thus count on a "recuperation" of the third molars even with a projected calculated deficiency of available space of up to $6 \mathrm{~mm}$.

The experimental results and the statistics that support the methods for calculating the posterior growth and the prognostic ex ante of conservation/ sacrifice of the mandibular third molars have been presented in detail (posterior growth and prognosis for the eruption of the mandibular third molars).

\section{The "feed-back" posterior box anterior box}

This is the interesting element of this step. Practitioners can often:

\section{CLINICAL CASE}

B. Odessa presented to our office in September 2007. She is a young cheerful girl, barely 11 years old. She
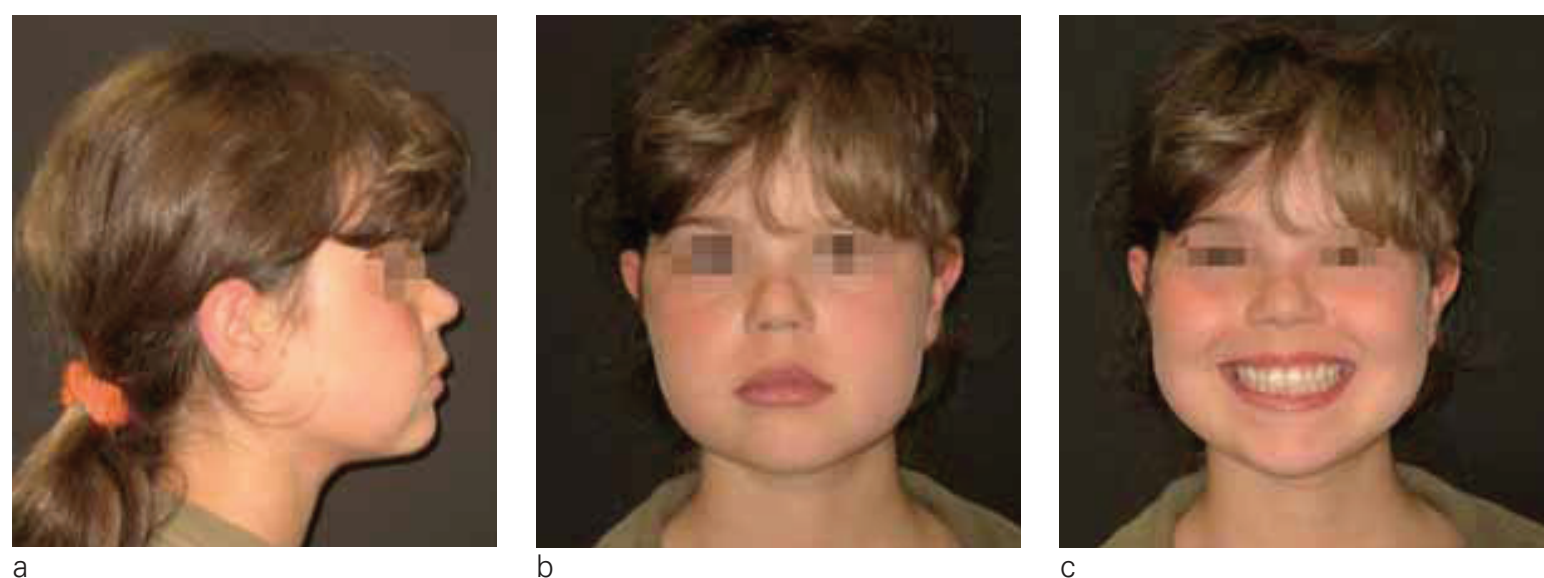

had already stated that her sub-nasal profile was protrusive which she attributed to her "fleshy" lips" (Fig. 5 a to c).

- re-evaluate the program of extraction;

- re-evaluate the loss of systematic (automatic) loss of anchorage associated with extractions;

- re-evaluate the mechanics in removing, for example, the TIM II (Class II traction), that causes of the loss of anchorage, and using mini-screws;

- re-evaluate incisor repositioning, etc.

\section{Synthesis}

We are convinced that, taking into account of the evolution of medical ethics of better mechanical assessment of positioning of molar groups aided by screw anchorage, that taking posterior sectors of the arch into consideration, which is often neglected today, will be inevitable tomorrow.

C

Figure 5

Profile, face and smile portraits; beginning of treatment: September 2007; 11 a. 


\section{Diagnosis}

The clinical exam shows an occlusal Class II tendency, with an excessive

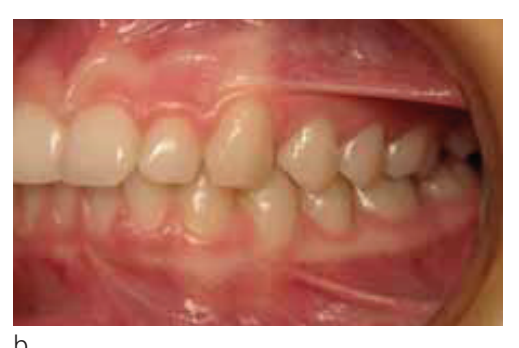

b overjet. The mandibular crowding indicates a lack of room. It is less present in the maxilla due to the overjet. (Fig. 6 a to c, Fig. 7 a to c, Fig. 8 a and b).

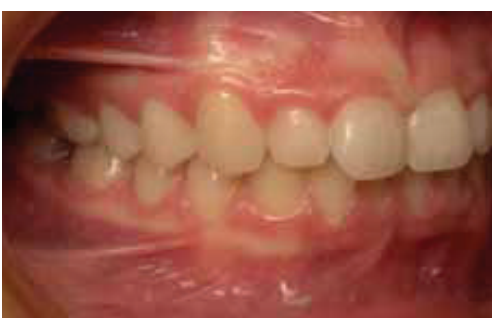

a

Figure 6

$a, b$, and c: Intraoral views right, frontal and left; start of treatment: September 2007; 11a.

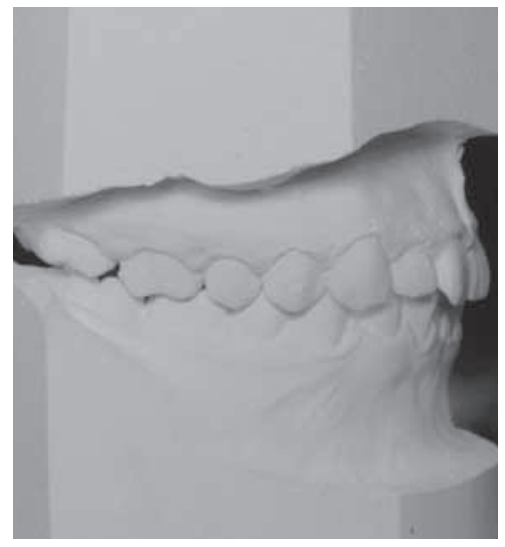

a

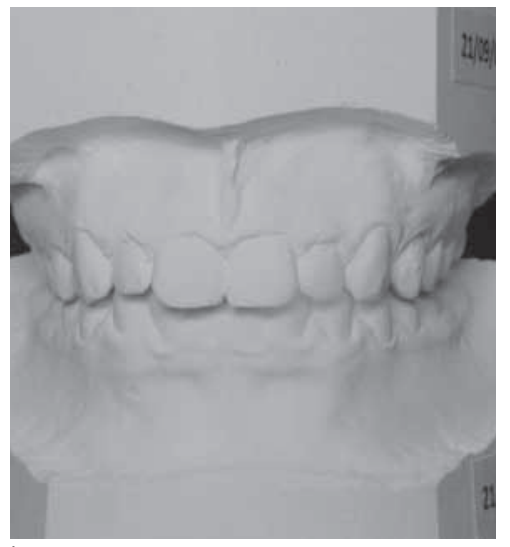

b

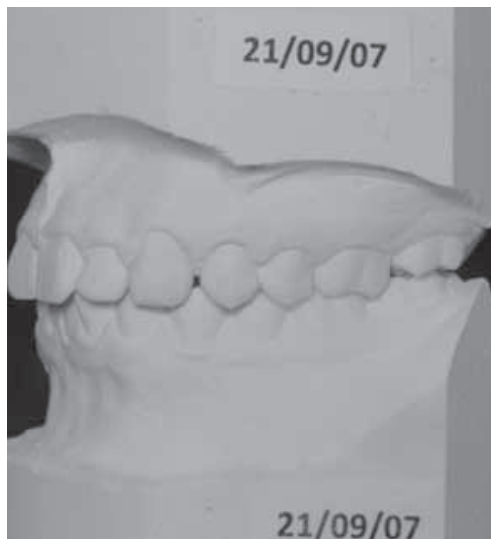

C

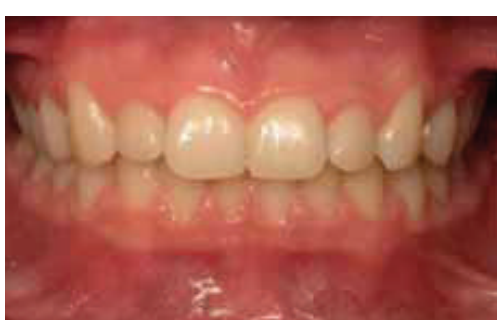

C

Figure 7

Right, frontal and left vestibular views of casts; start of treatment: September 2007; 11a.

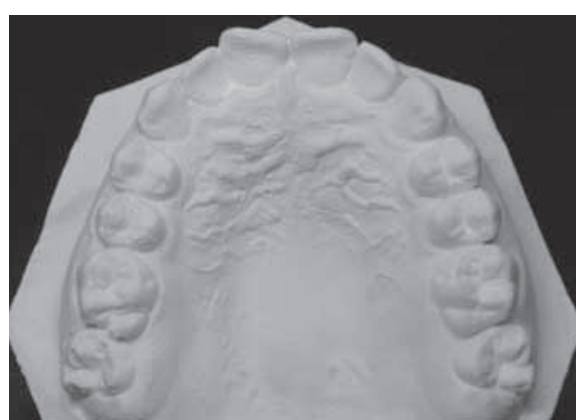

a

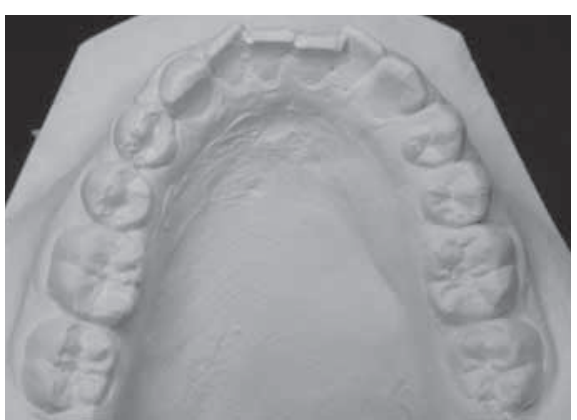

b

Figure 8

a and b: Maxillary and mandibular occlusal views of casts; start of treatment: September 2007; 11 . 

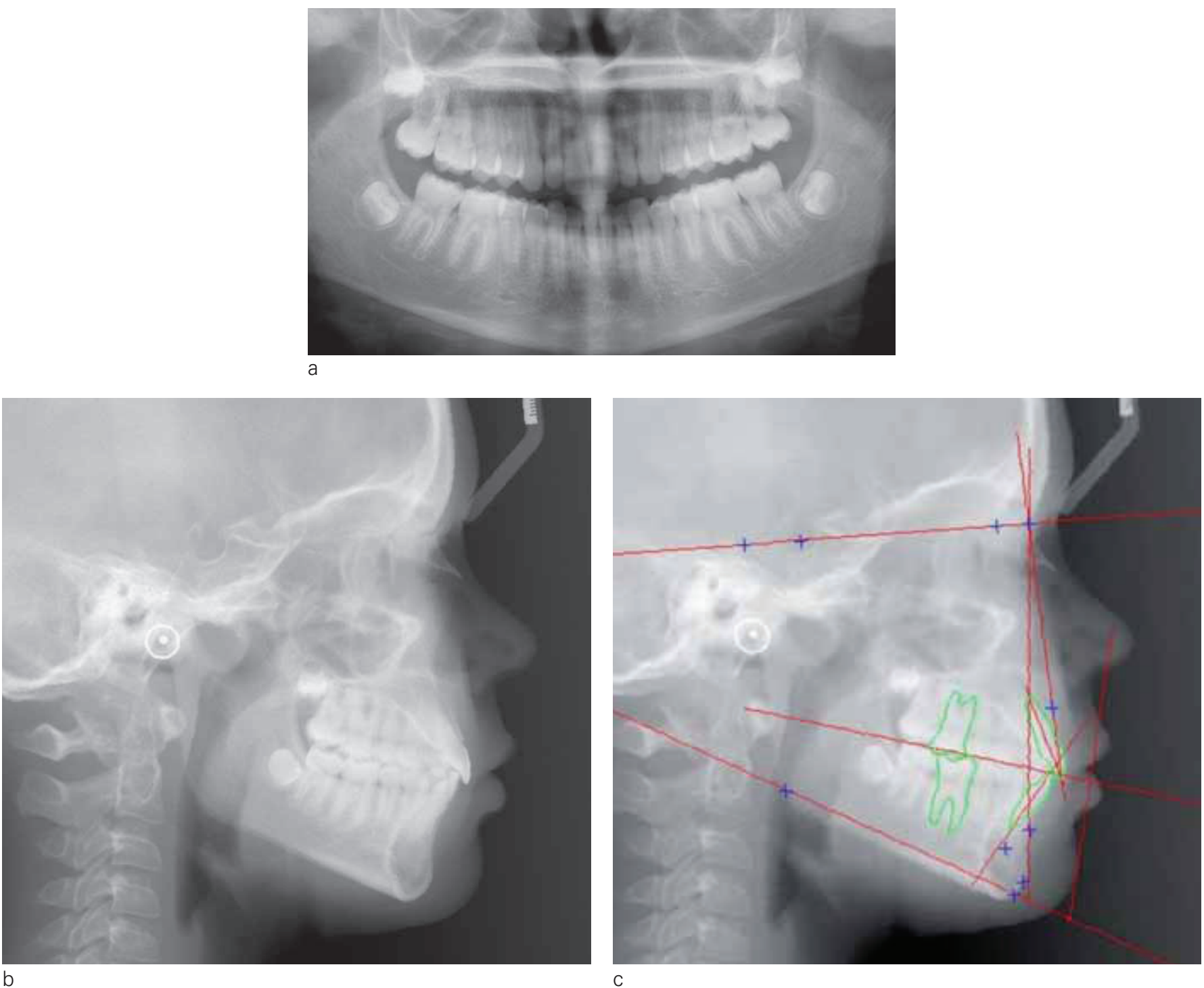

Figure 9

$a, b$ and c: Panoramic, lateral head film, and cephalometric tracing; start of treatment: September 2007; $11 a$.

The complete file (Fig. 9 a to c) confirms a strong skeletal Class II, that clinical exam had suggested (ANB $7.5^{\circ}$ ). The very strong compensations have reduced the occlusal Class II (1/ NA: $1 \mathrm{~mm}, 14^{\circ} ; 1 / \mathrm{NB}: 7.5 \mathrm{~mm}, 35^{\circ}$.

\section{Objectives and treatment plan}

The ideal chevron for a final ANB projected to be $5^{\circ}$ is written $(5$, $-1,3,1)$ (Fig. 10). The "anterior box" shows the need for special 


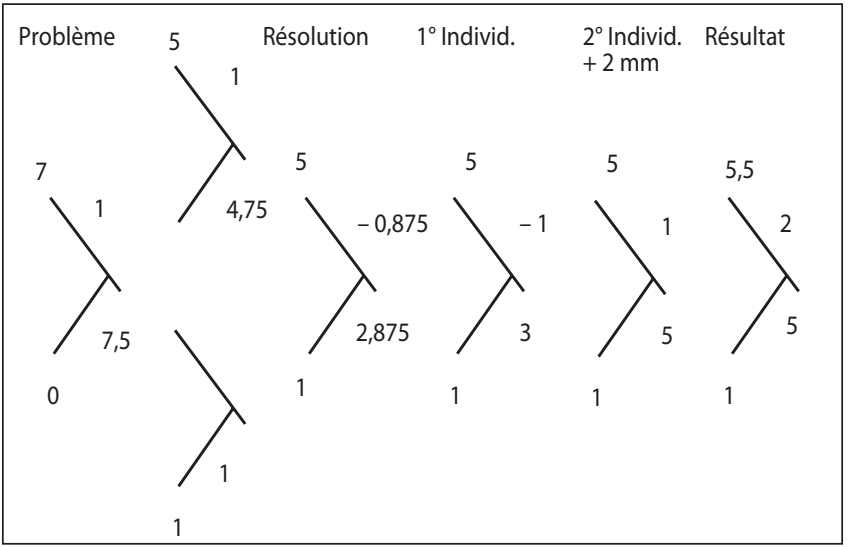

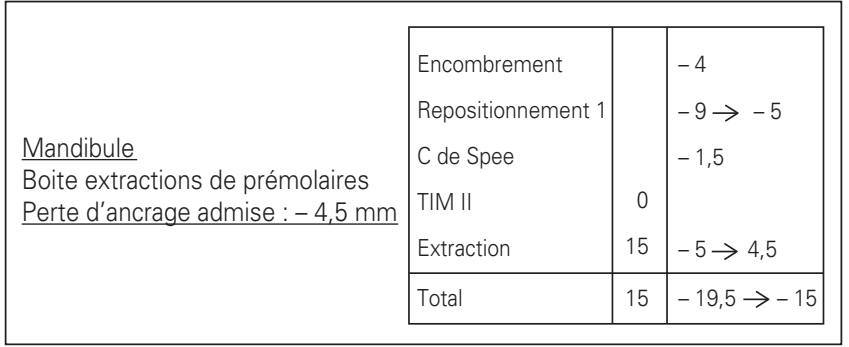

Figure 11

Steiner boxes: premolar extractions.

Figure 10

Steiner treatment objective chevrons.

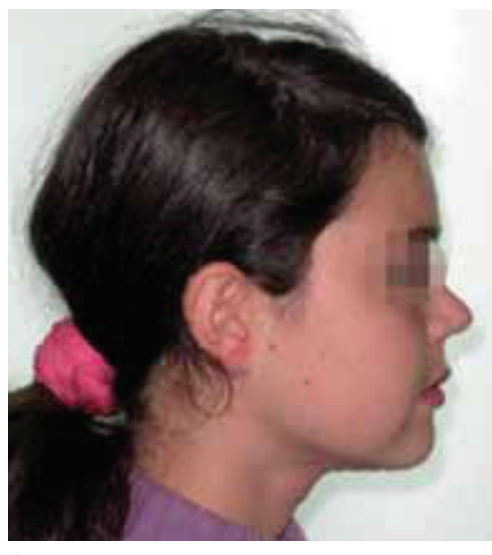

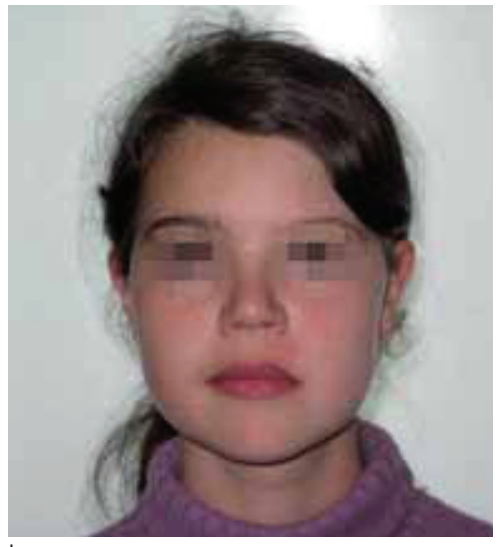

$\mathrm{b}$

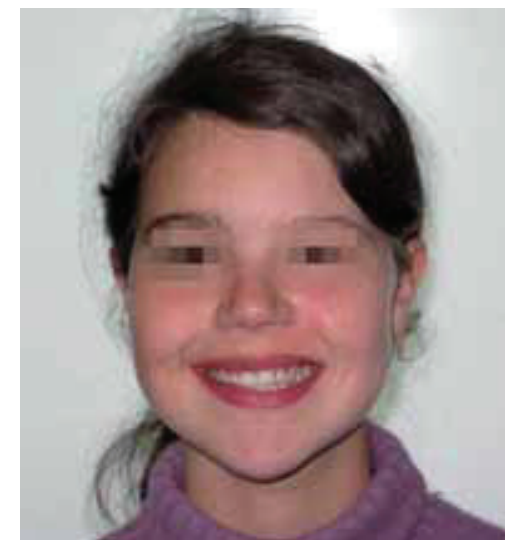

C

$\backsim$

$\varangle$

Figure 12

$a, b$ and c: profile, fontal and smile portraits: de-banding: 10/10; $14 y 1 \mathrm{~m}$.

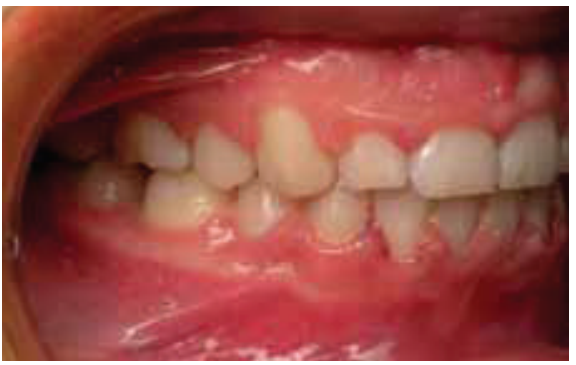

a

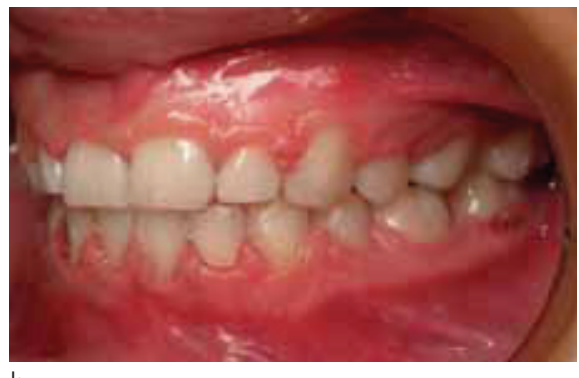

b

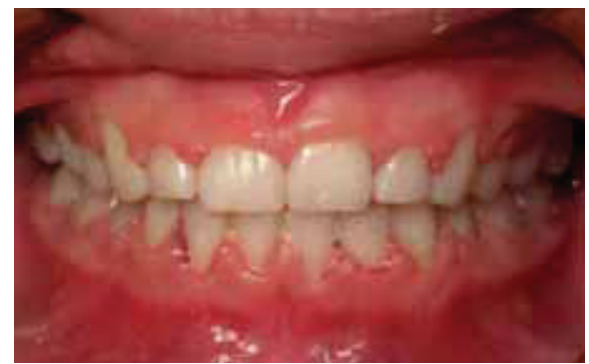

C

Figure 13

$a, b$, and c: Right, frontal and left intraoral views: de-banding: 10/10; 14y $1 \mathrm{~m}$. 


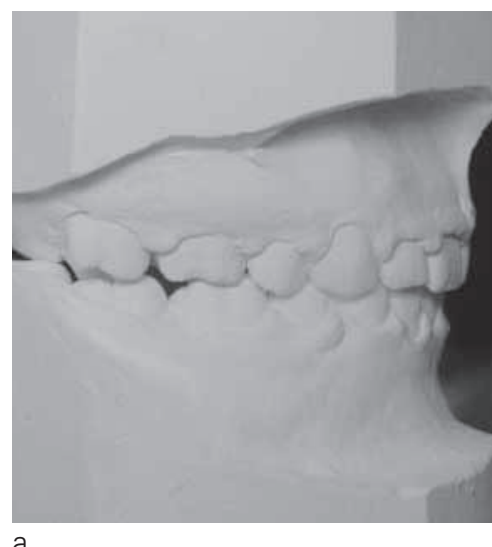

a

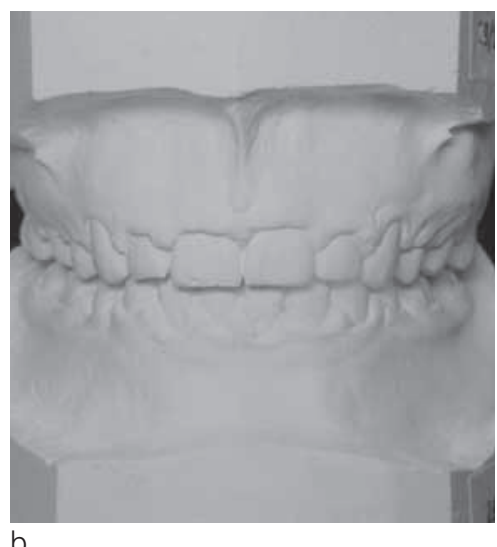

Figure 14

$a, b$ and c: Right, frontal and left vestibular casts views; de-banding; 10/10; $14 y 1 \mathrm{~m}$.
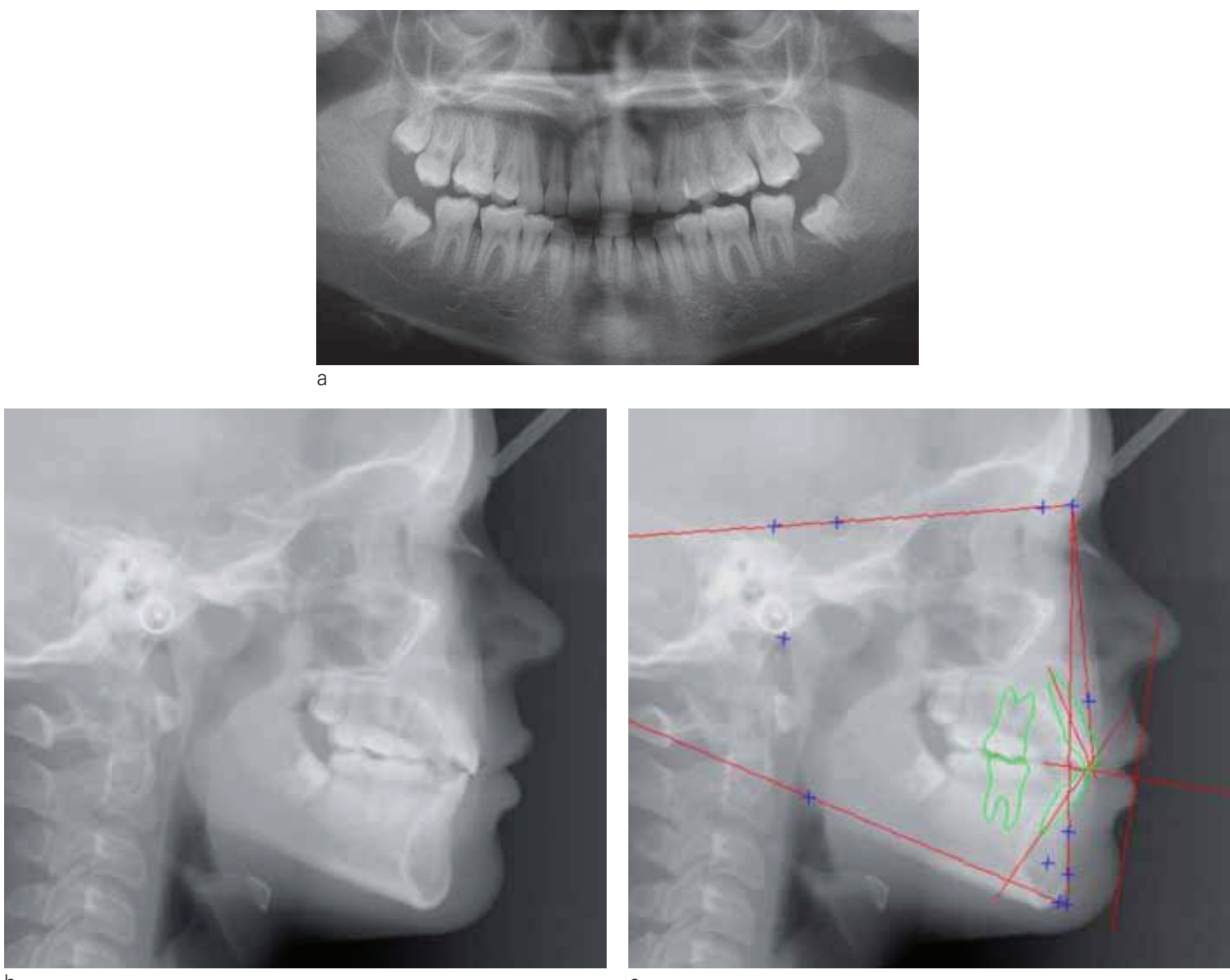

c

Figure 15

$a, b$, and c: Panoramic, lateral head film and tracing: de-banding: 10/10; 14y 10m. 
Calculation of the post treatment arch length discrepancy acc. TWEED ext PM w/o ext PM

\begin{tabular}{|l|r|l|}
\hline Actual available space (distal 7) & +4 & \\
$3^{\text {rd }}$ molar diameters & -22 & \\
Actual saving of space (+/-) & -18 & \\
\hline Predicted growth & +9 & \\
Loss of molar anchorage & -4.5 & \\
Estimated saving of space & -4.5 & \\
\hline The prognosis for the conservation of the $3^{\text {rd }}$ molars is favorable with \\
a theoretical space deficit estimated to be less than or equal to $-6 \mathrm{~mm}$.
\end{tabular}

Tweed's calculations show a space deficit of -4.5 , but we know

that the deficit can be modified

- the 8's can be in place in the arch with a covering by the anterior border of the ramus of $23 \mathrm{~mm}(+6 \mathrm{~mm})$

- the re-establishment of the Curve of Spee gives $2 \mathrm{~mm}$ of additional space.

\section{Figure 16}

Boîte espace postérieur (calcul de Tweed).

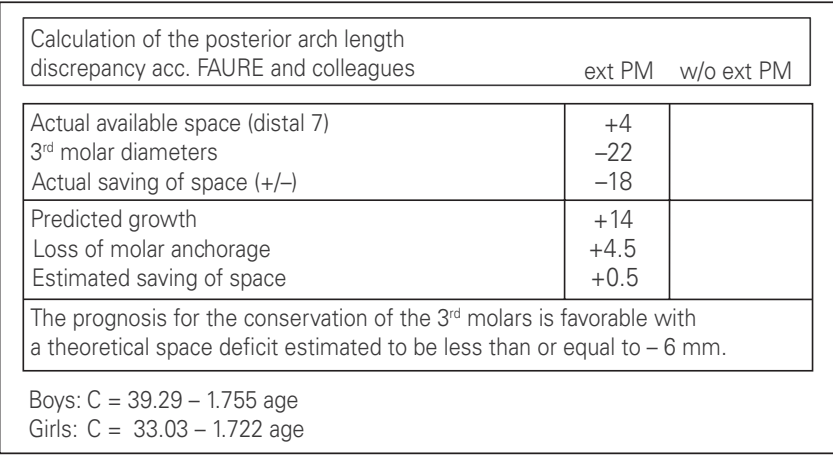

Figure 17

Posterior space box (growth calculations according to Faure).

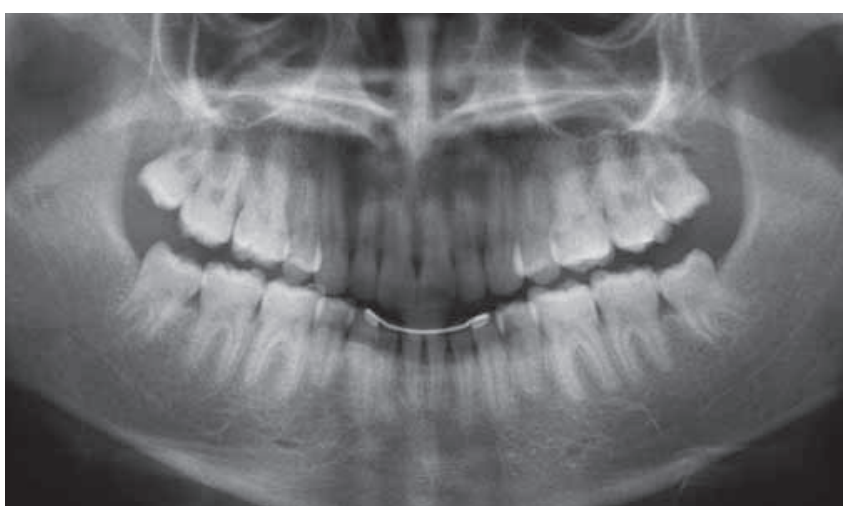

Figure 18

Panoramic: retention: 1/12; $15 y 4 m$.

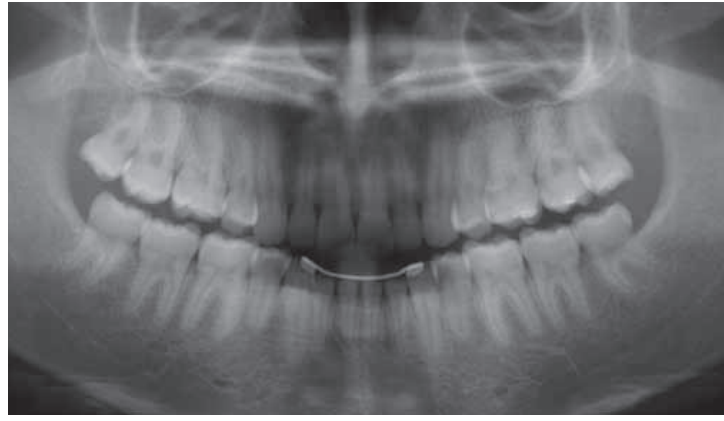

$\backsim$
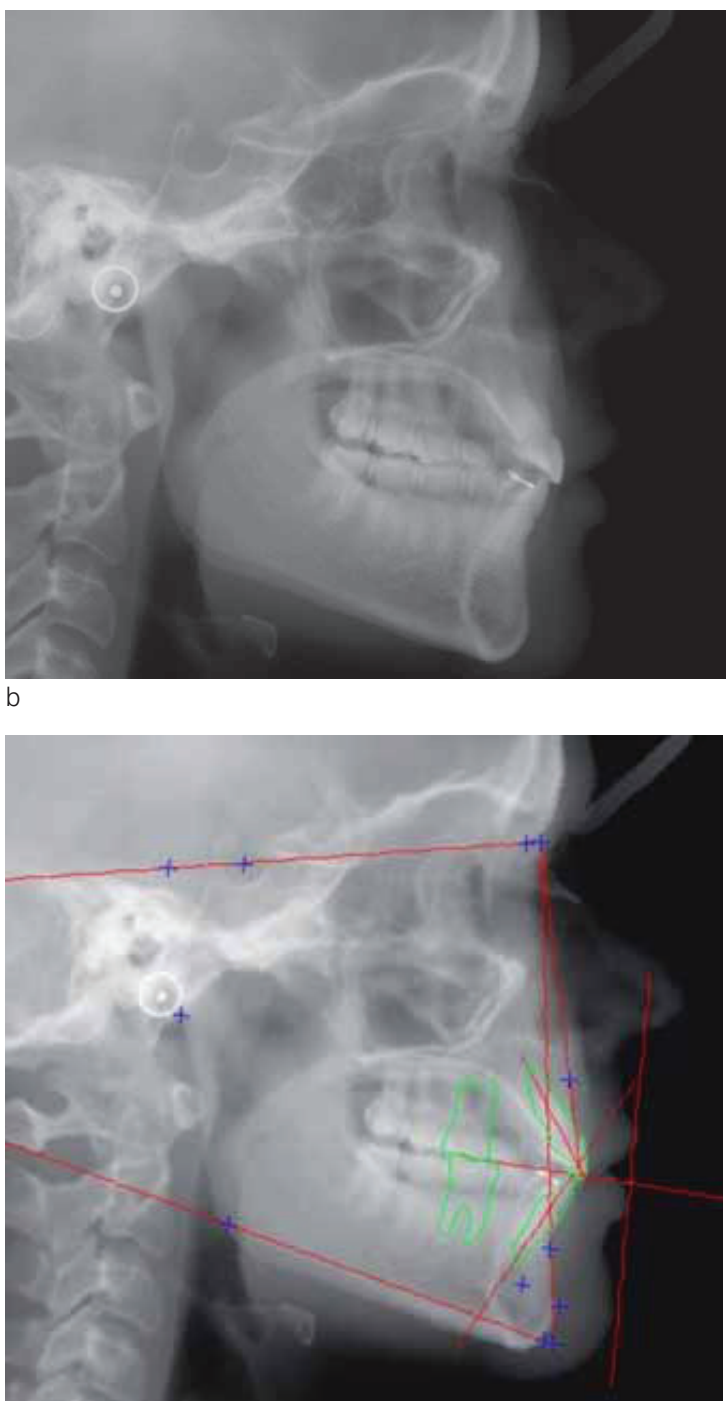

Figure 19

$a, b$ and $c$ : Panoramic, lateral head film and tracing; 2y $10 \mathrm{~m}$ after de-banding $(16 \mathrm{y} 11 \mathrm{~m})$. 


\begin{tabular}{|l|c|c|c|}
\hline \multicolumn{1}{|c|}{ Odessa } & $9 / 07$ & $10 / 10$ & $08 / 13$ \\
& $11 \mathrm{a}$ & $14 \mathrm{a} 1 \mathrm{~m}$ & $16 \mathrm{a} 11 \mathrm{~m}$ \\
\hline SNA & 93 & 90,5 & 93 \\
\hline SNB & 86 & 85,5 & 87,5 \\
\hline ANB & 7 & 5 & 5,5 \\
\hline SND & 81,5 & 82 & 83,5 \\
\hline $1 / \mathrm{NAmm}$ & 1 & 1,5 & 2 \\
\hline $1 / \mathrm{NA}^{\circ}$ & 14 & 18 & 20 \\
\hline $1 / \mathrm{NBmm}^{\circ}$ & 7,5 & 4 & 5 \\
\hline $1 / \mathrm{NB}^{\circ}$ & 35 & 34,5 & 35 \\
\hline Pog/NB & 0 & 1 & 1,5 \\
\hline $1 / 1$ & 123,5 & 122 & 119,5 \\
\hline Occl/SN & 16 & 13 & 13 \\
\hline GoGn/SN & 29 & 27 & 24,5 \\
\hline SE & 17 & 16 & 15,5 \\
\hline SL & 59 & 54 & 58,5 \\
\hline
\end{tabular}

Table I: Steiner analysis start of treatment, de-banding, out of retention.

precautions when using anchorage (mini-screws?).

The posterior box shows the impossibility of accommodating the 8's (Fig. 11).

The limitation of the mandibular incisor repositioning strongly limits the demands on anchorage control (it is possible to lose $2.25 \mathrm{~mm}$ on each side) and it assures the conservation of the 8's, while increasing the

\begin{tabular}{|l|c|c|c|}
\hline \multicolumn{1}{|c|}{ Odessa } & $9 / 07$ & $10 / 10$ & $08 / 13$ \\
& $11 \mathrm{a}$ & $14 \mathrm{a} 1 \mathrm{~m}$ & $16 \mathrm{a} 11 \mathrm{~m}$ \\
\hline FMIA & 54 & 55 & 56 \\
\hline FMA & 27 & 25 & 24 \\
\hline IMPA & 99 & 100 & 100 \\
\hline SNA & 93 & 90,5 & 93 \\
\hline SNB & 86 & 85,5 & 87,5 \\
\hline ANB & 7 & 5 & 5,5 \\
\hline AoBo & $-0,5$ & $-0,5$ & $-1,5$ \\
\hline Occl /F & 16 & 13 & 13 \\
\hline Z & 13 & 8,5 & 9,5 \\
\hline U lip & 15,5 & 15 & 12 \\
\hline T chin & 14 & 13,5 & 13,5 \\
\hline HFP & 41 & 40,5 & 43 \\
\hline HFA & 65 & 60 & 61 \\
\hline HFP/HFA & 0,63 & 0,7 & 0,7 \\
\hline
\end{tabular}

Table II : Tweed analysis start of treatment, de-banding, out of retention.

posterior space due to the loss of anchorage.

Treatment is then begun with extraction of 14-24-34-44 with light anchorage force. The "salvage" of the 8 's is part of our specifications.

\section{Treatment}

Treatment undertaken in July 2008 was begun under conditions of excellent

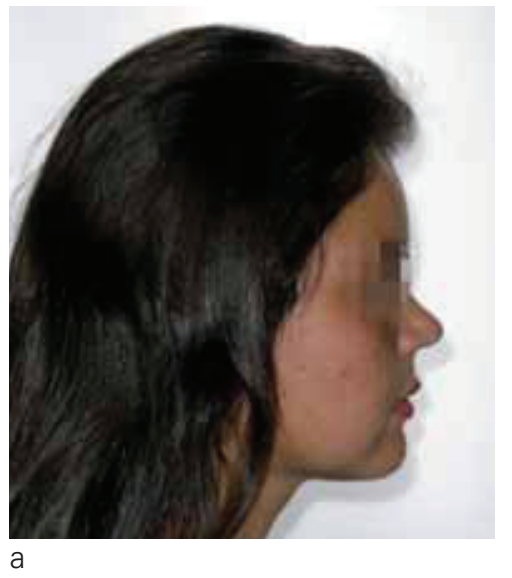

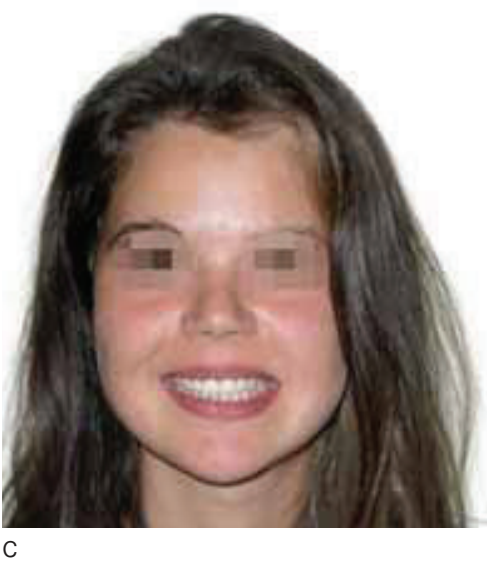

Figure 20 


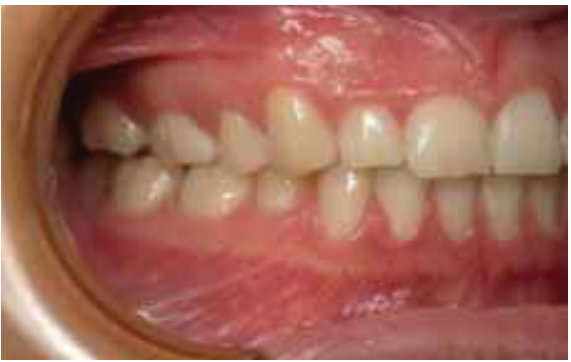

a

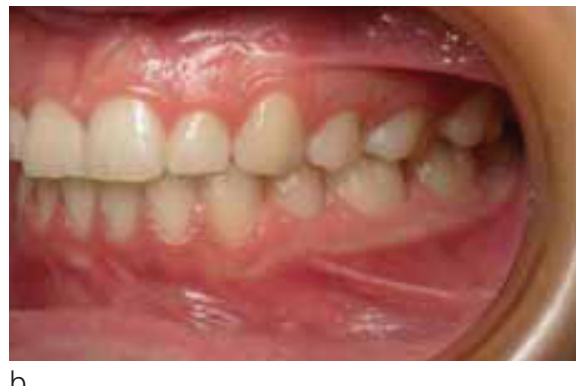

b

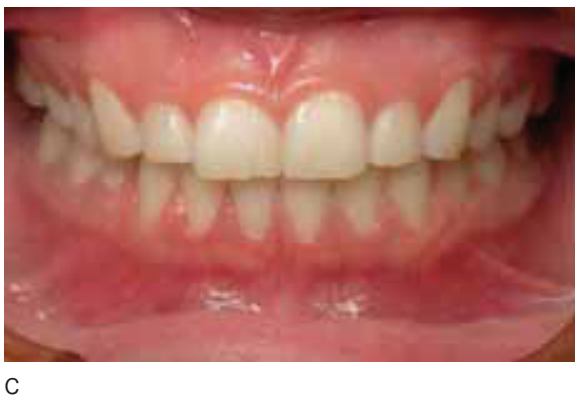

Figure 21

$a, b$, and $c$ : Intraoral views right frontal and left; 2 y $10 \mathrm{~m}$ after de-banding $(16 y 11 \mathrm{~m}$.

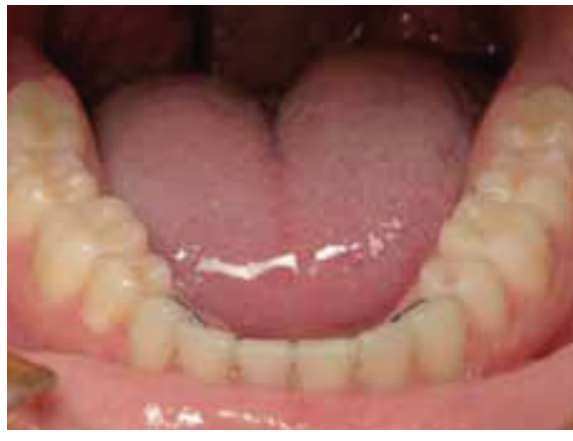

a

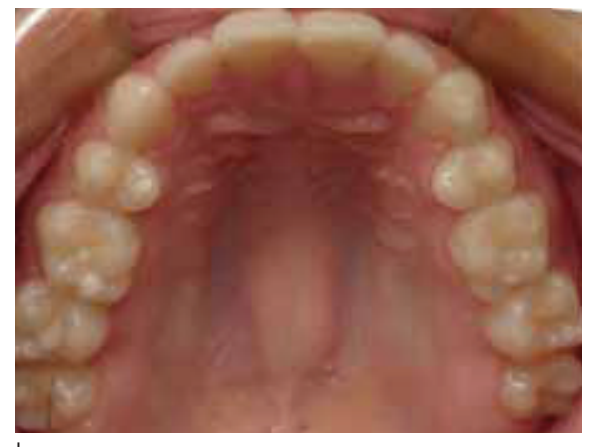

b

$\backsim$

$\varangle$

Figure 22

a and b: Maxillary and mandibular intraoral occlusal views; 2 y $10 \mathrm{~m}$ after de-banding (16y $11 \mathrm{~m})$.

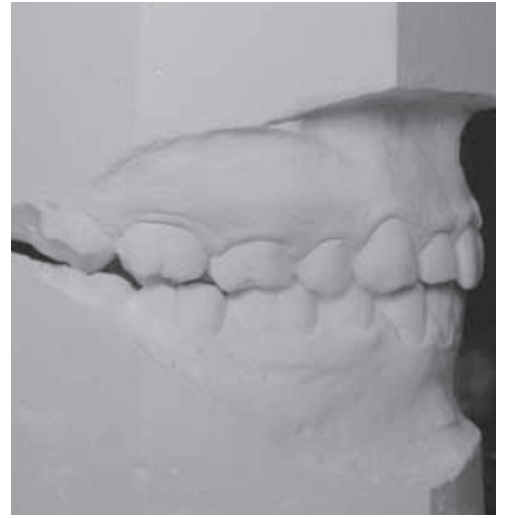

a

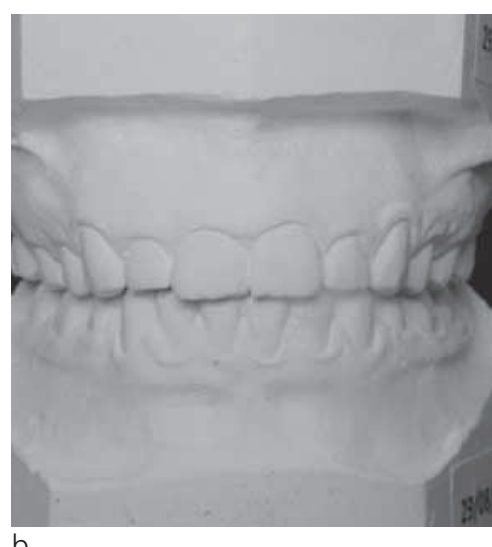

Figure 23

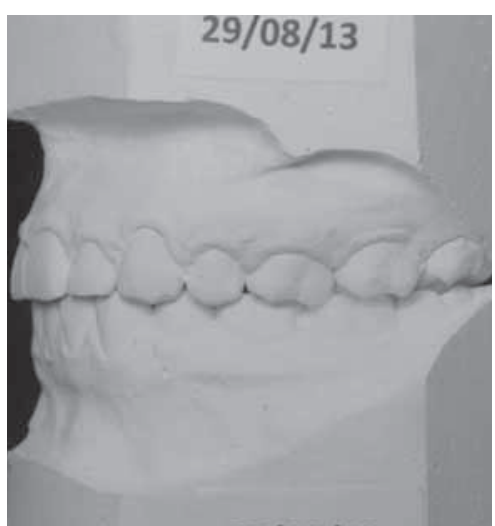

C

$a, b$ and c: Right, frontal, and left vestibular views of casts; 2 y $10 \mathrm{~m}$ after de-banding $(16 y 11 \mathrm{~m})$. 


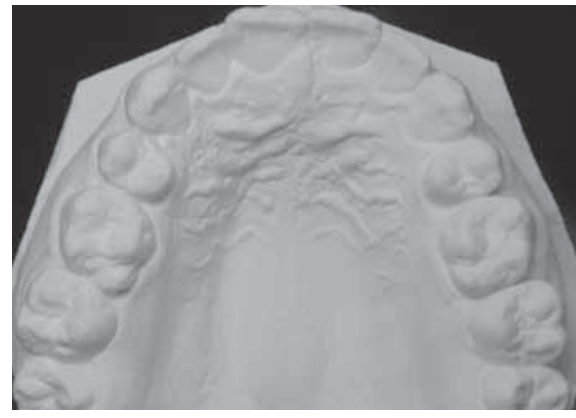

a

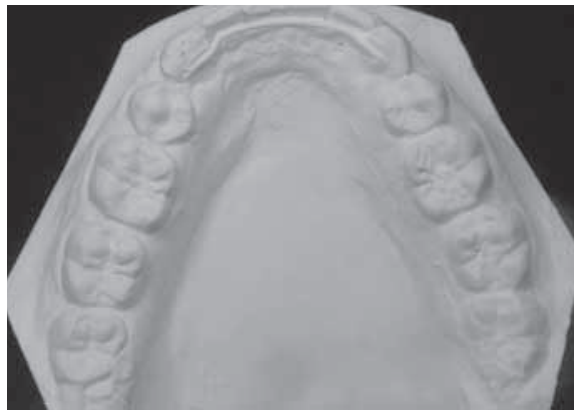

b

Figure 24

Maxillary and mandibular occlusal views of casts; 2 y $10 \mathrm{~m}$ after de-banding $(16 \mathrm{y} 11 \mathrm{~m})$.

cooperation with moderate use of directional forces. It was achieved in October 2010 (2 years and 3 months) (Fig. 12 a to c, Fig. 13 a to c, Fig. 14 a to c).

On de-banding day, the image of the wisdom teeth is worrisome (Fig. 15 a to c); but we have confidence in our statistics: we know that, contrary to what is taught by the TweedMerrifield School (Fig. 16), posterior growth does not stop at 14 years in girls and 16 years in boys (Fig. 17).

The final check radiographs (Fig. 18, Fig. 19 a to c) show the incisor positions conforming to our objectives, with an acceptable slight bimaxillary protrusion within the ideal range. The following confirms the excellent stability (Tables I and II).

The patient is radiant (Fig. 20 a to $\mathrm{c}$.

Here the third molars erupted rapidly and came into normal position without delay (Fig. 21 a to c, Fig. 22 a and b, Fig. 23 a to c, Fig. 24 a and b), to our great satisfaction.

\section{Conclusion}

This case illustrates well the advantage of a global analysis, namely, taking into account the entire dentition (including the third molars) and not only at 11-12 years, but also with an eye on the future that the formulas for the estimate of growth allow. This global analysis of course has as its goal the optimization of the choice of extractions, so as to reduce the number of teeth sacrificed.

\footnotetext{
Conflict of interest: The author declares no conflict of interest.
} 